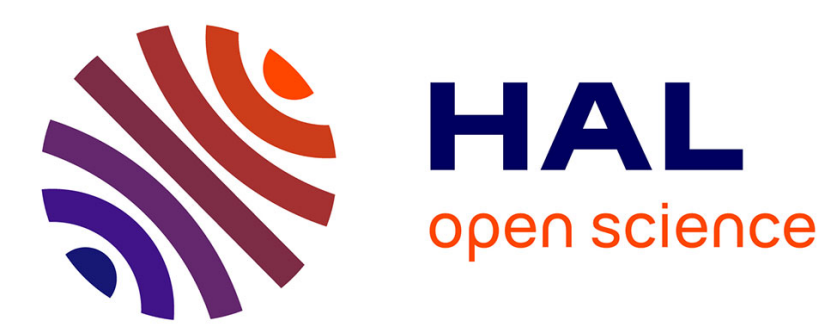

\title{
On the Representation of Winning Strategies of Finite Games by Groups and Neutrosophic Groups
}

Mohammad Abobala

\section{To cite this version:}

Mohammad Abobala. On the Representation of Winning Strategies of Finite Games by Groups and Neutrosophic Groups. 2021. hal-03232006

\section{HAL Id: hal-03232006 https://hal.science/hal-03232006}

Preprint submitted on 21 May 2021

HAL is a multi-disciplinary open access archive for the deposit and dissemination of scientific research documents, whether they are published or not. The documents may come from teaching and research institutions in France or abroad, or from public or private research centers.
L'archive ouverte pluridisciplinaire HAL, est destinée au dépôt et à la diffusion de documents scientifiques de niveau recherche, publiés ou non, émanant des établissements d'enseignement et de recherche français ou étrangers, des laboratoires publics ou privés. 


\title{
On the Representation of Winning Strategies of Finite Games by Groups and Neutrosophic Groups
}

\author{
Mohammad Abobala, Tishreen University, Syria
}

\begin{abstract}
In this paper, we show that for a finite game with two players A, B:
Each winning strategy of the first player A can be represented by a neutrosophic subgroup of the neutrosophic group $\left(Z_{2} \times \ldots \times Z_{2}\right)(I)$, and each winning strategy of the second player $\mathrm{B}$ can be represented by an elementary abelian group $Z_{2} \times$. . $\times Z_{2}$.

Also, we introduce the concept of algebraically relative games and present some examples on it.
\end{abstract}

Key Words : Group, Neutrosophic group, Winning strategy

\section{1-Introduction :}

Groups are always very useful in representations of algebraic structures, and finite games as a finite steps can be considered.

Neutrosophy as a branch of philosophy introduced by F.Smarandache has many applications in the real world and the mathematical concepts. The concept of neutrosophic group had been defined in[2] as a generalization of classical groups, subgroups and normal subgroups also were defined and studied.

The most useful understanding of neutrosophic group has been written in [3], we consider $\mathrm{N}(\mathrm{G})$ as a union of $\mathrm{G}$ and $\mathrm{GI}$ i.e $\mathrm{N}(\mathrm{G})=\left\{x_{1}, x_{2}, \ldots x_{1} I, x_{2} I, \ldots ; x_{i} \in G\right\}$.

We will use a neutrosophic subgroup to represent every winning strategy of player A, and a classical group to represent every winning strategy of player B.

This research maybe very useful in the progression of game theory by algebraic views.

\section{2-Preliminaries :}

\section{Definition $2.1:[2]$}

Let $\left(\mathrm{G},{ }^{*}\right)$ be a group . Then the neutrosophic group is generated by $\mathrm{G}$ and I under * denoted by $\mathrm{N}(\mathrm{G})=\{\langle G \cup I\rangle, *\}$.

I is called the indeterminate element (neutrosophic element) with the property $I^{2}=I$.

The most useful understanding of this definition has been written in [3], we consider $\mathrm{N}(\mathrm{G})$ as a union of $\mathrm{G}$ and $\mathrm{GI}$ i.e $\mathrm{N}(\mathrm{G})=\left\{x_{1}, x_{2}, \ldots x_{1} I, x_{2} I, \ldots ; x_{i} \in G\right\}$.

Definition 2.2 :[2] 
Let $\mathrm{N}(\mathrm{G})$ be a neutrosophic group, then a neutrosophic subgroup is a subset of $\mathrm{N}(\mathrm{G})$ contains a proper subgroup of $\mathrm{G}$.

\section{Remark2.3 :[2]}

Neutrosophic subgroup is not a group but contains a group.

\section{Definition $2.4:[5]$}

An abelian group $\mathrm{G}$ is called elementary abelian if it is isomorphic to $Z_{n} \times \ldots \times Z_{n}$ for such a positive integer $n$.

For concepts like game, analyzing game, and combinatorial game see [4].

\section{3-Main results and discussion :}

Suppose that G is a game with finite steps. Two players A, B play this game, they make their steps alternately, i.e (their choices) from a finite set of objects $\mathrm{S}=\left\{x_{1}, \ldots x_{n}\right\}$.

If we reach to a position which A cannot chose any object then B is the winner, and conversely $\mathrm{A}$ is the winner.

Without affecting the generality we can suppose that the alternating choices of two players can be realized as :

\begin{tabular}{|c|c|}
\hline $\mathrm{A}$ & $\mathrm{B}$ \\
\hline & \\
\hline & \\
\hline$\ldots$ & $\ldots \ldots$ \\
\hline
\end{tabular}

We say that a step $\mathrm{i}$ is complete if both players were able to chose objects without being losers.

For each complete step, we can represent it by a bijective map f: $S \rightarrow S$ wich permutes the chosen objectives in this step an fixes the rest of unchosen objectives, i.e if the player A chooses the element $x_{i}$ and B chooses $x_{j}$, then we represent this complete step by the map : $\mathrm{f}: S \rightarrow S$ with $\mathrm{f}\left(x_{i}\right)=x_{j}$ and $\mathrm{f}\left(x_{j}\right)=x_{i}$ and $\mathrm{f}\left(x_{t}\right)=x_{t}$ for each $t \neq i, j$,

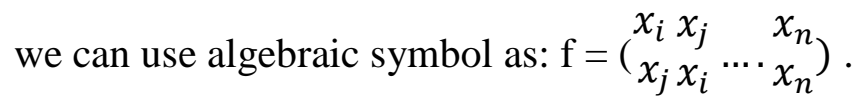

\section{Theorem 3.1 :}

Let $f_{i}$ be the representation of the complete step i, then $f_{i}{ }^{2}=\mathrm{I}$ (of order 2), where $\mathrm{I}$ is the identity map on $\mathrm{S}$.

Proof :

It is easy to see that $f_{i} o f_{i}\left(x_{i}\right)=f_{i}\left(x_{j}\right)=x_{i}$. 
We represent the beginning position of the game by I (identity map).

\section{Theorem 3.2 :}

Each winning strategy of second player B can be represented by a group with type

Proof :

If $\mathrm{B}$ has a winning strategy, then we will reach to a position that B can choose and player A cannot, as follows :

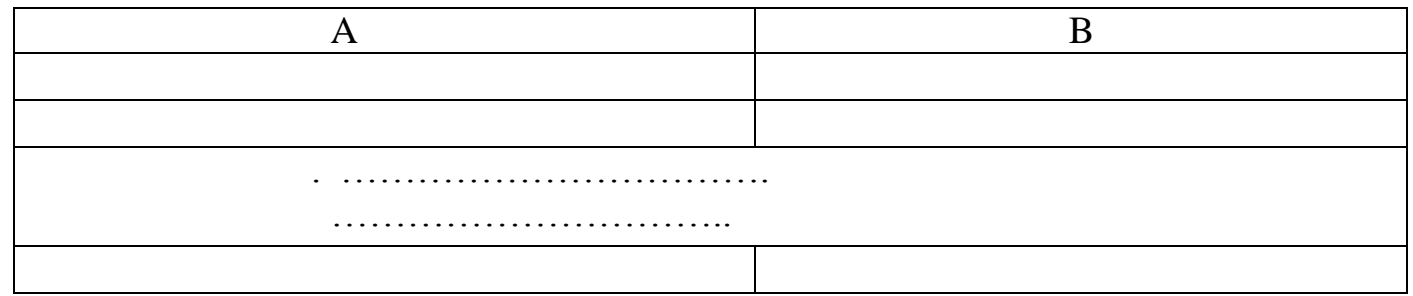

We assume that the number of steps is $\mathrm{k}$, we remark that all steps are complete and each step's representation is a bijective with order 2 , so the group generated by all representations is $\left(Z_{2}\right)^{k}$.

We call the previous group by a strategy representation.

\section{Definition 3.3 :}

If we reach to a position which A can chose and B cannot, we represent it by the indeterminate map J, which it means that A can pick an object and B cannot.

Remark: The indeterminate map $J$ has the property $J^{2}=J$, we mean by this property that if we reach to a winning position of player $\mathrm{A}$, then the next position is the same.

\section{Theorem 3.4 :}

Each winning strategy of first player A can be represented by a neutrosophic subgroup with type .

Proof :

If A has a winning strategy then we will reach to a position that $\mathrm{A}$ can choose and then B cannot, as the following :

\begin{tabular}{|c|c|}
\hline $\mathrm{A}$ & $\mathrm{B}$ \\
\hline & \\
\hline & \\
\hline
\end{tabular}




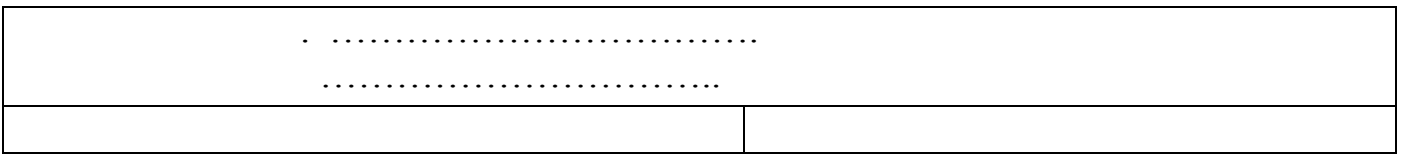

We assume that the number of steps is $\mathrm{k}+1$, we remark that all steps are complete unless the last step. The group generated by all steps unless the last one is $\left(Z_{2}\right)^{k}$.

For the last step we can represent it by the indeterminate $J$, thus the strategy representation is the neutrosophic subgroup of $\mathrm{N}\left(\left(Z_{2}\right)^{k}\right)$ which is set :

\section{Result 3.5 :}

If $\mathrm{A}$ is the winner then the strategy representation is a neutrosophic group, and if $\mathrm{B}$ is the winner then the strategy representation is a classical group Definition 3.6 :

(a) If the player B has a winning strategy, then the winning strategy with minimum representation group order is called the perfect strategy of B.

(b) If the player A has a winning strategy, then the winning strategy with minimum representation group order is called the perfect strategy of A.

\section{Definition 3.7 :}

If $\mathrm{H}, \mathrm{K}$ are two finite games, we say that $\mathrm{H}$ is algebraically relative or $(\mathrm{H}-\mathrm{ar}-\mathrm{K})$, if there is a perfect strategy of the Player A in both games with the same representation neutrosophic group, or a perfect strategy of the player B in both games with same representation group .

Remark : The essential meaning of algebraically relative games is that they have winning strategies with the same number of steps.

\section{Example 3.8 :}

Suppose that we have two players A , B which they are playing Wythoff game with $(3,2)$ as a beginning position, A at least needs two steps to win, we can clarify it by the following example:

\begin{tabular}{|l|l|}
\hline A & B \\
\hline$(1,2) \quad($ after the choice of A $)$ & $(1,1)$ \\
\hline A chooses $(1,1)$ and wins & \\
\hline
\end{tabular}

The representation neutrosophic subgroup is $Z_{2} \cup\{J\}$

Let the same players play the HIM-Game defined in [4]. The beginning position is $(2,4,5,10)$, A has a perfect strategy as 


\begin{tabular}{|l|l|}
\hline A & B \\
\hline$(2,4,2,2)$ after A choice & $(2,4)$ after B choice \\
\hline A chooses $(2,4)$ and wins & \\
\hline
\end{tabular}

The representation neutrosophic subgroup is $Z_{2} \cup\{J\}$, thus the previous two games are algebraically relative.

\section{4-Conclusion}

In this research, we have introduced a representation of winning strategies of finite alternating games by groups and neutrosophic groups. Also, we have introduced the notion of algebraically relative games and gave many examples.

\section{References}

[1]Babinkostova.L , Cosket.S , Kontradyuk.D , Navert.S , Potter.S and Scheepers.M , A study of games over finite groups, publication at www.researchgate.net ,July 2015, Boise State university $\mathrm{pp}(1-3)$

[2] Kandasamy .V and Samarandache ,F , some neutrosophic algebraic structures and neutrosophic N-algebraic structures, Hexis , Phonex , Arizona 2006, p.p 219

[3] Chalapathi .T and Kumar.K , neutrosophic graphs of finite groups , neutrosophic sets ans systems, vol 15, (2017)

[4]Dabash.M , Al-Najjar.H and Barbara.H , Create HIM , the adjusted NIM game , and analyses its winning strategy , PH.D thesis , university of Aleppo press , 2013 , pp20-130

[5] Haushi M , Algebraic structures , Tishreen university press , 2004 , p.p 112-140.

[6] Sankari, H., and Abobala, M., "Neutrosophic Linear Diophantine Equations With two Variables", Neutrosophic Sets and Systems, Vol. 38, pp. 22-30, 2020.

[7] Sankari, H., and Abobala, M." n-Refined Neutrosophic Modules", Neutrosophic Sets and Systems, Vol. 36, pp. 1-11. 2020.

[8] Alhamido, R., and Abobala, M., "AH-Substructures in Neutrosophic Modules", International Journal of Neutrosophic Science, Vol. 7, pp. 79-86 . 2020.

[9] Hatip, A., Alhamido, R., and Abobala, M., "A Contribution to Neutrosophic Groups", International Journal of Neutrosophic Science", Vol. 0, pp. 67-76 . 2019.

[10] Abobala, M., " n-Refined Neutrosophic Groups I", International Journal of Neutrosophic Science, Vol. 0, pp. 27-34. 2020. 
[11] Sankari, H., and Abobala, M.," AH-Homomorphisms In neutrosophic Rings and Refined Neutrosophic Rings", Neutrosophic Sets and Systems, Vol. 38, pp. 101-112, 2020.

[12] Abobala, M, "n-Cyclic Refined Neutrosophic Algebraic Systems Of SubIndeterminacies, An Application To Rings and Modules", International Journal of Neutrosophic Science, Vol. 12, pp. 81-95 . 2020.

[13] Abobala, M., "Classical Homomorphisms Between n-refined Neutrosophic Rings", International Journal of Neutrosophic Science", Vol. 7, pp. 74-78. 2020.

[14] Hatip, A., and Abobala, M., "AH-Substructures In Strong Refined Neutrosophic Modules", International Journal of Neutrosophic Science, Vol. 9, pp. 110-116 . 2020.

[15] Sankari, H., and Abobala, M., "Solving Three Conjectures About Neutrosophic Quadruple Vector Spaces", Neutrosophic Sets and Systems, Vol. 38, pp. 70-77. 2020.

[16] Adeleke, E.O., Agboola, A.A.A., and Smarandache, F., "Refined Neutrosophic Rings II", International Journal of Neutrosophic Science, Vol. 2(2), pp. 89-94. 2020.

[17] Abobala, M., On Refined Neutrosophic Matrices and Their Applications In Refined Neutrosophic Algebraic Equations, Journal Of Mathematics, Hindawi, 2021

[18] Abobala, M., A Study of Maximal and Minimal Ideals of n-Refined

Neutrosophic Rings, Journal of Fuzzy Extension and Applications, Vol. 2, pp. 16-22, 2021.

[19] Abobala, M., " Semi Homomorphisms and Algebraic Relations Between Strong Refined Neutrosophic Modules and Strong Neutrosophic Modules", Neutrosophic Sets and Systems, Vol. 39, 2021.

[20] Abobala, M., "On Some Neutrosophic Algebraic Equations", Journal of New Theory, Vol. 33, 2020.

[21] Abobala, M., On The Representation of Neutrosophic Matrices by Neutrosophic Linear Transformations, Journal of Mathematics, Hindawi, 2021.

[22] Abobala, M., "On Some Algebraic Properties of n-Refined Neutrosophic Elements and n-Refined Neutrosophic Linear Equations", Mathematical Problems in Engineering, Hindawi, 2021

[23] Khaled, H., and Younus, A., and Mohammad, A., " The Rectangle Neutrosophic Fuzzy Matrices", Faculty of Education Journal Vol. 15, 2019. (Arabic version).

[24] Abobala, M., Partial Foundation of Neutrosophic Number Theory, Neutrosophic Sets and Systems, Vol. $39,2021$.

[25] F. Smarandache, Neutrosophic Theory and Applications, Le Quy Don Technical University, Faculty of Information technology, Hanoi, Vietnam, $17^{\text {th }}$ May 2016. 
[26] Abobala, M., Hatip, A., Olgun, N., Broumi, S., Salama, A,A., and Khaled, E, H., The algebraic creativity In The Neutrosophic Square Matrices, Neutrosophic Sets and Systems, Vol. 40, pp. 1-11, 2021.

[27]Alhamido, K., R., "A New Approach of neutrosophic Topological Spaces", International Journal of neutrosophic Science, Vol.7, 2020.

[28] Chellamani, P., and Ajay, D., "Pythagorean neutrosophic Fuzzy Graphs", International Journal of Neutrosophic Science, Vol. 11, 2021. 